\title{
Urban Interiority: Emerging Cultural and Spatial Practices
}

Discourses on the urban interior recently have emerged as a series of provocations and experimentations that highlight the critical understanding of the urban realm from the interiority perspective. The urban interior discussion has focused on the shift from viewing the urban interior in terms of location and spatial enclosure, to a setting for urban acts and inhabitation. The urban interior highlights urban settings' role as containers of urban life through encounters and occupations (Hinkel, 2011). The urban interior addresses urban places' ability to promote individuals' character within urban environments (Pimlott, 2018); provide spatial conditions that incorporate the experience of transition, movement and time (Poot et al., 2018); and become a setting ready to be transformed through a series of methods and techniques (Attiwill, 2011; Hinkel, 2011).

In the fast-moving development of modern global cities, the urban interior concept becomes increasingly important. Cities are fast becoming containers for contemporary spatial practice, with urban spaces becoming melting pots of diverse cultures and communities. The urban interior is characterised by its fluid character that "manifests itself as a social, economic, cultural or political construct that changes and evolves in response to fluctuating borders, multiplicity of identities and varying layers of sense of belonging" (Hadjiyanni, 2018, p. 398). The urban interior's role as a container of urban spatial practices raises some issues regarding the nexus of global contemporary culture and particular localities. The emergence of new culture, driven by changing economic situations and the advancement of technology, elicits

Correspondence Address: Paramita Atmodiwirjo, Department of Architecture, Faculty of Engineering, Universitas Indonesia, Kampus UI, Depok 16424, Indonesia. Email: paramita@eng.ui.ac.id 
some challenges in understanding how spatial practice changes over time. Simultaneously, it poses another challenge as to how particular culture endures within global and modern urban culture.

Viewing urban settings from the interiority perspective allows us to comprehend unique local character in particular contexts. The urban interior is manifested as a setting of urban life "through activities and practices in particular localities" (Hinkel, 2011, p. 82). Many urban places are characterised by the uniqueness of local spatial practices, distinguishing them from global urban settings. Many such local practices cannot be separated from the cultural aspects embedded in actors' lives, their activities and spatial settings. Culture's uniqueness, to some extent, could define particular forms of engagement between people and spaces in the urban environment. The particularities of urban actions, performed by urban actors, could lead to narratives on particular uses and the distinctive meanings of particular urban settings (Atmodiwirjo et al., 2019). Understanding this uniqueness offers the potential for a further investigation of the urban interior within the context of contemporary urban practice.

The cultural and spatial practice emerging from the urban interior could be represented through various media and could lead to various design strategies for urban intervention that celebrate cultural practices in our urban environment. Design strategies for the urban interior aim at placemaking, an attempt to create an interior condition that amplifies people's engagement with the urban environment, through "specific character, materiality, atmosphere, and evidence of relations, through which people may be more conscious of themselves and others, the world and their place in it." (Pimlott, 2018, p. 10). The making of the urban interior is essentially the making of the condition of an interior that could promote the character of its actors in their engagement with these places. One of the critical emergent questions is how to create an urban interior that can become a container for society's dynamic cultural practice.

This issue of Interiority presents a collection of works that illustrate the expanded understanding of the urban interior, especially in relation to cultural and spatial practice in urban contexts. The first three articles in this issue illustrate the stories of different urban interior settings in which spatial practices become unique due to their local characters. They demonstrate various forms of interior experience and inhabitation emerging from cultural practice in society. Alison B. Snyder shares her experience with the culture of collecting and browsing through books in the city as a form of intimate relations between the self and the urban. Through stories 
about two sahaflar streets in Istanbul, where such traditional bookselling practices occur, she discovers the layered interiors of the individual and collective experiences, comprising the urban interior experience.

Gregory Marinic, Rebekah Radtke and Gregory Luhan investigate the intertwined aspects of Chinese hutongs and American alleyways. This investigation examines the urban spatial setting as a trans-scalar medium that connects across regions and cultures. Arif Rahman Wahid, Kristanti Dewi Paramita and Yandi Andri Yatmo argue for the role of the immaterial interior in conveying particular stories about spatial practice. In particular, they examine inscriptions as a medium that represents the stories of practice in the traditional production setting as a form of resistance to traditional culture within global urban life.

The next three articles examine the possibilities of various media, models and typologies as tools to establish the condition of the interior capable of responding to society's dynamic spatial practices. These tools are useful for reading, comprehending and intervening in the urban interior, as they may represent the relationship between the urban and the self, space and experience, and spatial setting and intangible cultural values. Vahid Vahdat investigates film as a medium that reveals how the urban interior becomes a stage for cultural, ideological and political values in society. A detailed analysis of the cinematic elements demonstrates urban interior settings' role in providing multiple narratives on social issues.

Bie Plevoets and Shailja Patel examine the idea of hortus conclusus as an urban interior model implemented in the renovation of a museum. Such a model demonstrates the spatial porosity that enables a setting to establish a dialogue with its contexts. Sergio Lopez-Pineiro argues for the need to think beyond interiority as a typology that reveals the essence of the built environment as the basis of design practice. He proposes the idea of design practice being no longer constrained to a particular topology, but as an attempt to create openings to locate types within the globalised culture.

The practice of urban interior design also should be able to look toward the future of our urban spatial practice. The ability to predict how our life could change in the future becomes important in manoeuvring within fast-changing global urban life. This issue's final article, by Thea Brejzek and Lawrence Wallen, illustrates the co-design process between academia and industry in responding to how society will live in the future. The design studio becomes a laboratory in which the scenario of future living is examined and became the basis of designing the interior. 
This issue presents multiple perspectives on understanding the urban interior, raising arguments on how its spatial condition could perform as a container of cultural practice, while simultaneously offering possibilities on manoeuvring within the urban interior context through various ways of reading, interpretation and intervention. These perspectives and approaches promise further possibilities to expand our interior architectural practice in responding not only to current contemporary practice, but also to the future of urban inhabitation.

\section{References}

Atmodiwirjo, P., Johanes, M., \& Yatmo, Y. A. (2019). Mapping stories: Representing urban everyday narratives and operations. Urban Design International, 24(4), 225-240. https://doi. org/10.1057/s41289-019-00100-x

Attiwill, S. (2011). Urban and interior: Techniques for an urban interiorist. In R. U. Hinkel \& S. Attiwill (Eds.), Urban interior: Informal explorations, interventions and occupations (pp. 1124). Spurbuchverlag.

Hadjiyanni, T. (2018). Interiors as global constructs: Framing culture and design discourses in a world of movement. In G. Marinic (Ed.), The interior architecture theory reader (pp. 397-406). Routledge.

Hinkel, R. U. (2011). Private encounters and public occupations: A methodology for the exploration of public space. In R. U. Hinkel \& S. Attiwill (Eds.), Urban interior:Informal explorations, interventions and occupations (pp. 79-89). Spurbuchverlag.

Pimlott, M. (2018). Interiority and the conditions of interior. Interiority, 1(1), 5-20. https://doi.org/10.7454/in.v1i1.5

Poot, T., De Vos, E., \& Van Acker, M. (2018). Thinking beyond dualities in public space: The unfolding of urban interiority as a set of interdisciplinary lenses. Interiors, 9(3), 324-345. https://doi. org/10.1080/20419112.2019.1622235 